\title{
PROPOSAL TOMOGRAPHIC CLASSIFICATION FOR INTRA-ARTICULAR DISTAL RADIUS FRACTURES
}

\section{PROPOSTA DE CLASSIFICAÇÃO TOMOGRÁFICA PARA AS FRATURAS INTRA-ARTICULARES DA EXTREMIDADE DISTAL DO RÁDIO}

\author{
Valdênia das Graças Nascimento ${ }^{1}$, Antonio Carlos da Costa ${ }^{2}$, Leandro Rodrigues da Silva ${ }^{1}$, Diego Figueira Falcocchio ${ }^{2}$, \\ Ivan Chakkour ${ }^{2}$, Sergio Luiz CheCCHia ${ }^{2}$ \\ 1. Universidade Federal do Triângulo Mineiro, Uberaba, MG, Brazil. \\ 2. Department of Orthopedics, Hand Surgery Group, Irmandade da Santa Casa de Misericórdia de São Paulo, São Paulo, SP, Brazil.
}

\section{ABSTRACT}

Objective: The objective of this study was to present a proposal tomographic classification for intra-articular distal radius fractures. Methods: This descriptive study was based on observing tomographic images from 74 patients with distal radius fractures. The cases were grouped by similarity according to the presence of several parameters which determine fracture complexity; the results of the descriptive analysis were transcribed as tomographic classification. Results: The proposal tomographic classification for intra-articular distal radius fractures comprised three major groups and nine sub-groups, which are organized by increasing severity according to the presence of spacing between articular fragments, angulation, loss of radial height, cortical depression, and associated dislocation. Conclusion: This proposal tomographic classification for intra-articular distal radius fractures can help professionals indicate therapeutic options. Level of Evidence IV; Case series.

Keywords: Classification. Radius fractures. Tomography.

\section{RESUMO}

Objetivo: O objetivo deste estudo foi apresentar a proposta de uma classificação tomográfica das fraturas intra-articulares da extremidade distal do rádio. Métodos: Este estudo descritivo baseou-se na observação de imagens tomográficas de 74 pacientes com fratura da extremidade distal do rádio. Os casos foram agrupados por semelhança de acordo com a presença de alguns parâmetros determinantes da complexidade da fratura. Os resultados da análise descritiva foram transcritos na forma de uma classificação tomográfica. Resultados: A classificação tomográfica proposta para as fraturas intra-articulares da extremidade distal do rádio compreendeu três grupos maiores e nove subgrupos, organizados em ordem crescente de gravidade, de acordo com a presença de espaçamento entre os fragmentos articulares, desvio angular, perda da altura radial, afundamento cortical e luxação associada. Conclusão: Esta classificação tomográfica proposta para as fraturas intra-articulares da extremidade distal do rádio pode auxiliar os profissionais na indicação da conduta terapêutica. Nível de Evidência IV; Série de casos.

Descritores: Classificação. Fraturas do rádio. Tomografia.

Citation: Nascimento VG, Costa AC, Silva LR, Falcocchio DF, Chakkour I, Checchia SL. Proposal tomographic classification for intra-articular distal radius fractures. Acta Ortop Bras. [online]. 2018;26(1):54-8. Available from URL: http://www.scielo.br/aob.

\section{INTRODUCTION}

Distal radius fractures are the most common lesions of the upper limb, accounting for $10-12 \%$ of all human skeletal fractures. ${ }^{1}$ Organizing fractures into widely recognized classifications is important for determining and planning treatment options. ${ }^{2} \mathrm{~A}$ number of authors have attempted to simplify the current classification systems available, despite the challenges of obtaining excellent reliability, guaranteeing ideal treatment and predicting prognoses. ${ }^{3}$

Technological evolution of new imaging exams and research on improved radiographic views has furthered understanding of fracture patterns, articular involvement and allowed detailed observation of fragments hitherto not well visualized on traditional radiographic views. This advance has led to questioning of the current classifications in use, the criteria for instability, recommended treatments and prediction of prognoses.

Pruit et al. ${ }^{4}$ showed that computed tomography (CT) can disclose the involvement of the distal radio-ulnar joint in fractures better than radiographic imaging. In addition, the authors hold that CT is a highly useful exam for enhanced diagnostic elucidation, enabling easier and more reliable classification.

Given that the majority of classification systems used worldwide are based on observation of plain radiographs in two views, and drawing on previous studies by the Hand Surgery and Microsurgery Group investigating the influence of computed tomography

All authors declare no potential conflict of interest related to this article.

Work conducted at the Department of Orthopedics, Hand Surgery Group, Irmandade da Santa Casa de Misericórdia de São Paulo, São Paulo, SP, Brazil. Correspondence: Centro de Reabilitação, Hospital de Clínicas da UFTM. Rua da Constituição, 1009, Bairro Abadia, Uberaba, MG, Brazil. 38025-110. vallfmtm@yahoo.com.br 
on classifications and on treatment options for distal radius fractures, ${ }^{5}$ it was decided to propose a classification based on intra-articular fragments observed in tomographic images on sagittal, coronal and axial planes.

\section{MATERIAL AND METHODS}

A descriptive study of a tomographic classification for distal radius fractures was performed by observing radiographic and tomographic images from patients seen at a Hand Surgery Service in Santa Casa de São Paulo between June 2012 and October 2015. The study was approved by our Institution Review Board (IRB) and Research Ethics Committee with protocol number 571.246. This study exempts the Term of Free and Informed Consent.

Images were included from patients aged over 18 years, irrespective of gender, ethnicity or laterality, and who had radiographs for the four projections taken on admission (posteroanterior - PA; profile - $\mathrm{P} ; 45^{\circ}$ semi-pronated oblique- $\mathrm{PO} ; 45^{\circ}$ semi-supinated oblique - SO) as well as sagittal, axial and coronal tomographs. Patients who were skeletally immature or had inappropriate or insufficient images were excluded.

Related literature data on the main classifications in use and the key parameters determining the severity, instability and irreducibility of distal radius fractures were reviewed. Most of these are reported based on the observation of radiographic images. For the proposal classification, these were assessed in depth and correlated with tomographic images in coronal, sagittal and axial cross-sections. After tomographic interpretation of the traits of each fracture, the cases were grouped by similarity according to the presence of spacing and misalignment of the radiocarpal articulation and/or distal radio-ulnar articulation, to angulations and loss of radial height, fragmentation and articular depression, existence of radiocarpal and perilunate dislocations, and according to the treatment method recommended in the literature. Lastly, descriptive statistical analysis was carried out and the results obtained were transcribed in the form of a tomographic classification, and schematic drawings of the possible groups and subgroups were devised.

After assessment of the tomographic images on coronal, sagittal and axial planes of 74 cases of patients with distal radius fractures, a tomographic classification was devised for the intra-articular distal radius fractures comprising 3 major groups and organized in increasing order of severity of fracture pattern, treatment complexity, and determination of prognosis. Fractures in the first group exhibited no articular displacement or if present, this had spacing between articular fragments $<2 \mathrm{~mm}$; the second group included fractures with articular displacement $\geq 2 \mathrm{~mm}$; while the third group contained any intra-articular radiocarpal fracture associated with dislocation. Below, each group and subgroup are outlined in detail along with their respective particularities.

\section{Group I Fractures - Without articular displacement}

Encompass all intra-articular distal radius fractures whose spacing between articular fragments is $<2 \mathrm{~mm}$. These are divided into three sub-groups:

IA - Intra-articular fractures with involvement of the distal radio-ulnar or radiocarpal joint. These have single or multiple fracture lines in the distal radio-ulnar or radiocarpal articulation with spacing between fragments $<2 \mathrm{~mm}$, without dorsal angulation $\geq 20^{\circ}$. These fractures do not exhibit radial shortening $\geq 9 \mathrm{~mm}$. (Figure $1 \mathrm{~A}-\mathrm{C}$ )

IB - Intra-articular fractures with involvement of both the distal radio-ulnar and radiocarpal joint. These have single or multiple fracture lines in both articulations, with spacing between fragments $<2 \mathrm{~mm}$, without dorsal angulation $\geq 20^{\circ}$. These fractures do not exhibit radial shortening $\geq 9 \mathrm{~mm}$. (Figure $2 \mathrm{~A}-\mathrm{C}$ )
IC - Intra-articular fractures with involvement of both the distal radio-ulnar and radiocarpal joints. These have single or multiple fracture lines in both articulations, with spacing between fragments $<2 \mathrm{~mm}$. They have single or multiple metaphyseal fragments, with dorsal angulation $\geq 20^{\circ}$ and/or radial shortening $\geq 9 \mathrm{~mm}$. (Figure $3 \mathrm{~A}-\mathrm{C}$ )

\section{Group II Fractures - With articular displacement}

Encompass all intra-articular distal radius fractures whose spacing between intra-articular fragments is $\geq 2 \mathrm{~mm}$. These are divided into three sub-groups:
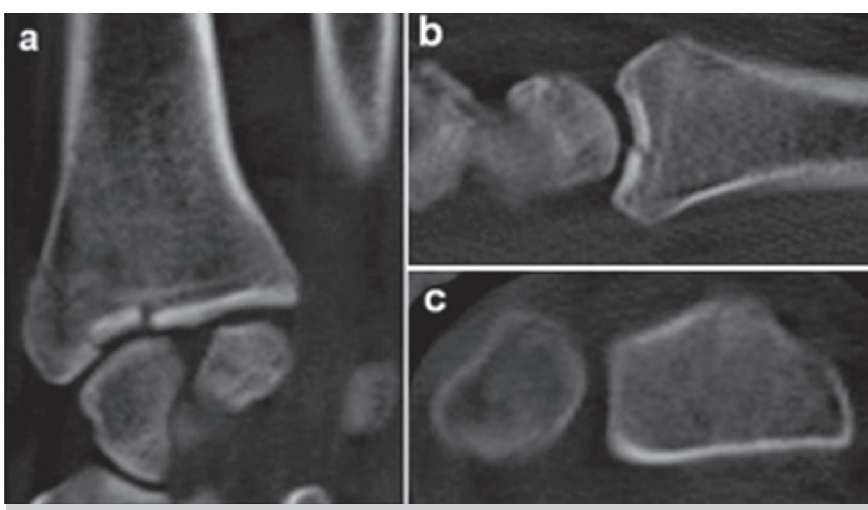

Figure 1. Tomographic images on coronal (A), sagittal (B) and axial (C) planes depicting intra-articular radiocarpal fracture of the distal end of the radius, without displacement, from subgroup IA.
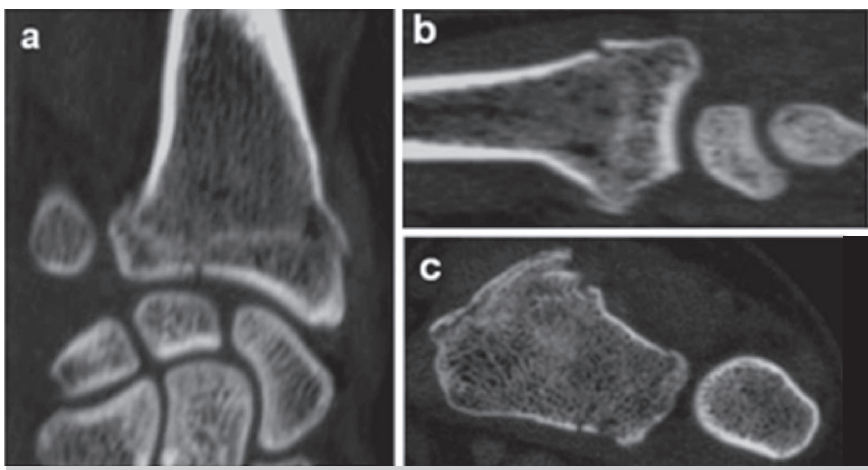

Figure 2. Tomographic images on coronal (A), sagittal (B) and axial (C) planes depicting intra-articular radiocarpal and distal radio-ulnar fracture of the distal end of the radius, without displacement, from subgroup IB.
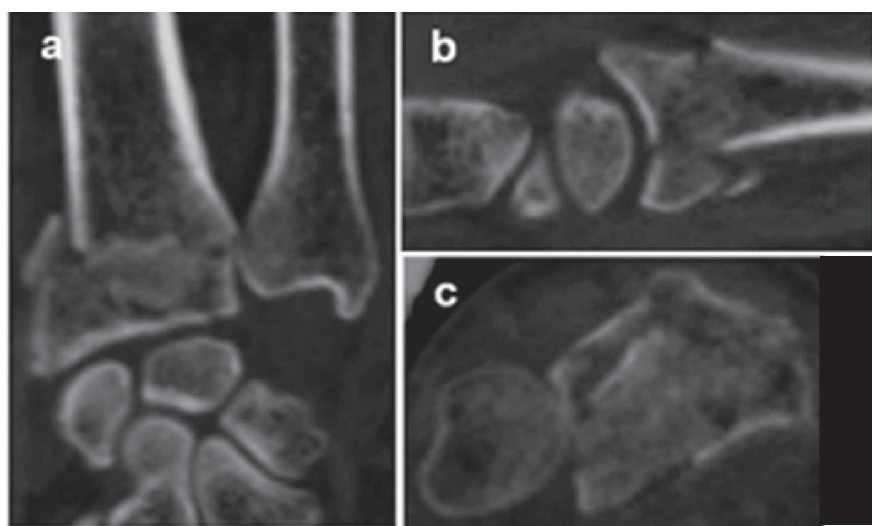

Figure 3. Tomographic images on coronal (A), sagittal (B) and axial (C) planes depicting intra-articular radiocarpal and distal radio-ulnar fracture of the distal end of the radius, associated with metaphyseal fragment, fragmented, with angulation and radial shortening, from subgroup IC. 
IIA - Intra-articular distal radio-ulnar and/or radiocarpal fractures with spacing between articular fragments $\geq 2 \mathrm{~mm}$, without dorsal angulation $\geq 20^{\circ}$. These fractures do not exhibit radial shortening $\geq 9 \mathrm{~mm}$. (Figure $4 \mathrm{~A}-\mathrm{C}$ )

IIB - Intra-articular distal radio-ulnar and/or radiocarpal fractures with spacing between articular fragments $\geq 2 \mathrm{~mm}$, associated with single or multiple metaphyseal fragments, and dorsal angulation $\geq$ $20^{\circ}$. May be associated with radial shortening $\geq 9 \mathrm{~mm}$. (Figure $5 \mathrm{~A}-\mathrm{C}$ ) IIC - Intra-articular distal radio-ulnar and/or radiocarpal fractures with depression of the scaphoid and lunate fossae and/or sigmoid notch, irrespective of the presence of dorsal angulation and/or radial shortening. (Figure 6A-C)

\section{Group III Fractures - Fractures-dislocations}

Encompass all intra-articular fractures of the distal end of the radius associated with dislocation of the radiocarpal or perilunate articulation of the carpus. May or may not have spacing between fragments, angulations, radial shortening or cortical depression. These are divided into three sub-groups:

IIIA - Intra-articular radiocarpal fractures with dorsal subluxation. May be associated with intra-articular distal radio-ulnar fracture. (Figure 7A-C) IIIB - Intra-articular radiocarpal fractures with volar subluxation. May be associated with intra-articular distal radio-ulnar fracture. (Figure 8A-C)

IIIC - Intra-articular radiocarpal and/or distal radio-ulnar fracture associated with perilunate dislocation of the carpus. (Figure 9A-C)
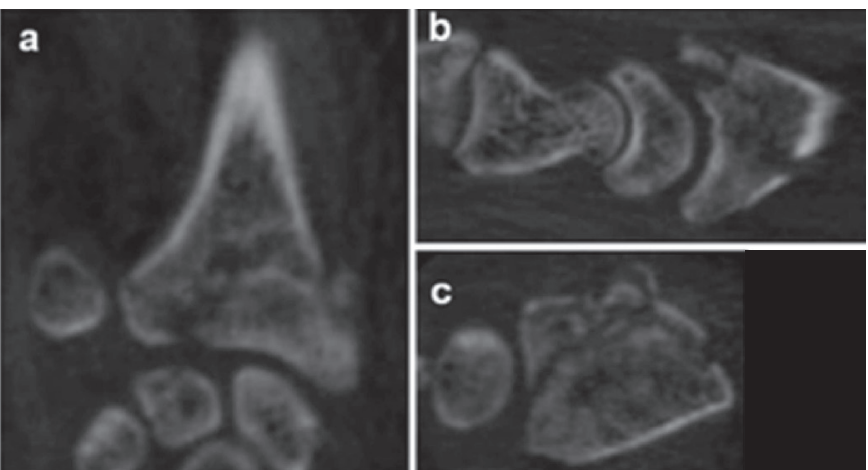

Figure 4. Tomographic images on coronal (A), sagittal (B) and axial (C) planes depicting intra-articular radiocarpal and distal radio-ulnar fracture of the distal end of the radius, with spacing between articular fragments $\geq 2 \mathrm{~mm}$, without angulation and without loss of radial height $\geq 9 \mathrm{~mm}$, from subgroup IIA.
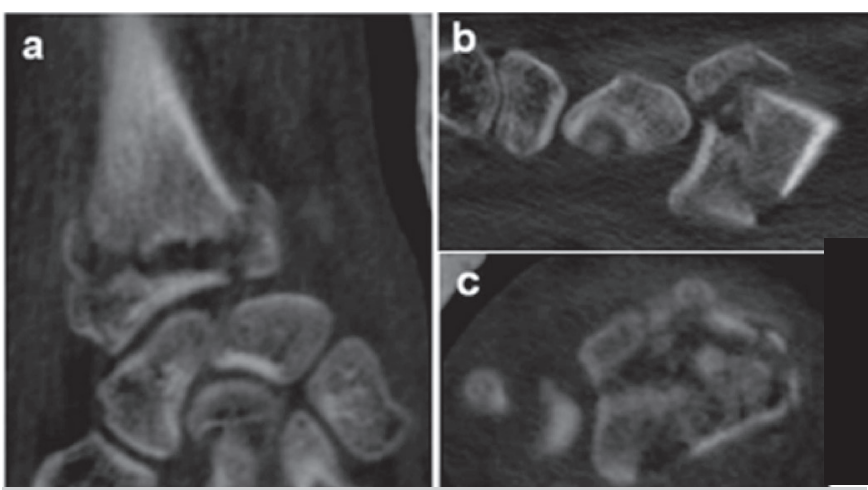

Figure 5. Tomographic images on coronal (A), sagittal (B) and axial (C) planes depicting intra-articular radiocarpal and distal radio-ulnar fracture of the distal end of the radius, with spacing between articular fragments $\geq 2 \mathrm{~mm}$, associated with metaphyseal fragment with angulation $>20^{\circ}$ and radial shortening $>9 \mathrm{~mm}$, from subgroup IIB.

\section{RESULTS}

The tomographic classification proposal has the advantage of encompassing the known intra-articular patterns into only three groups, comprising nine logical easy-to-memorize possibilities in increasing order of severity of articular involvement. (Figure 10) A total of 74 cases of patients with distal radius fractures were classified. All of the fractures had involvement of the radiocarpal
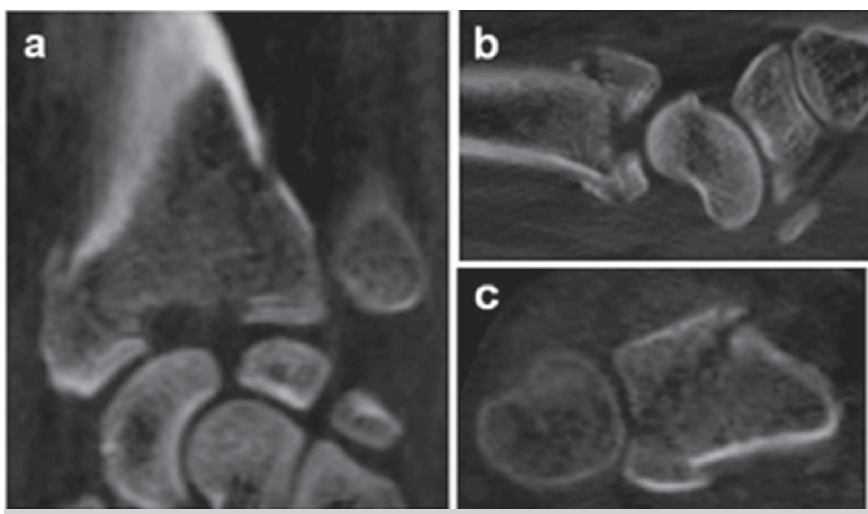

Figure 6. Tomographic images on coronal (A), sagittal (B) and axial (C) planes depicting intra-articular radiocarpal and distal radio-ulnar fracture of the distal end of the radius, with spacing between articular fragments $>2$ $\mathrm{mm}$, associated with depression of the scaphoid fossa, from subgroup IIC.
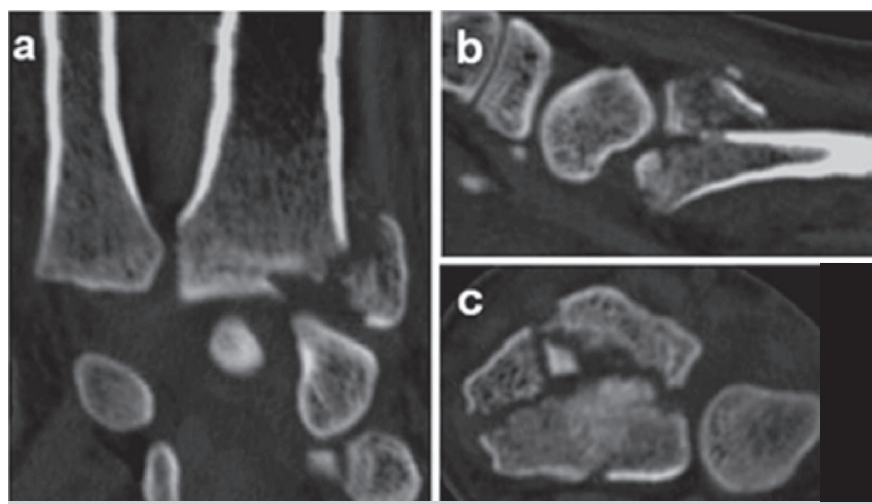

Figure 7. Tomographic images on coronal (A), sagittal (B) and axial (C) planes depicting intra-articular radiocarpal and distal radio-ulnar fracture of the distal end of the radius associated with radiocarpal dorsal dislocation, from subgroup IIIA.
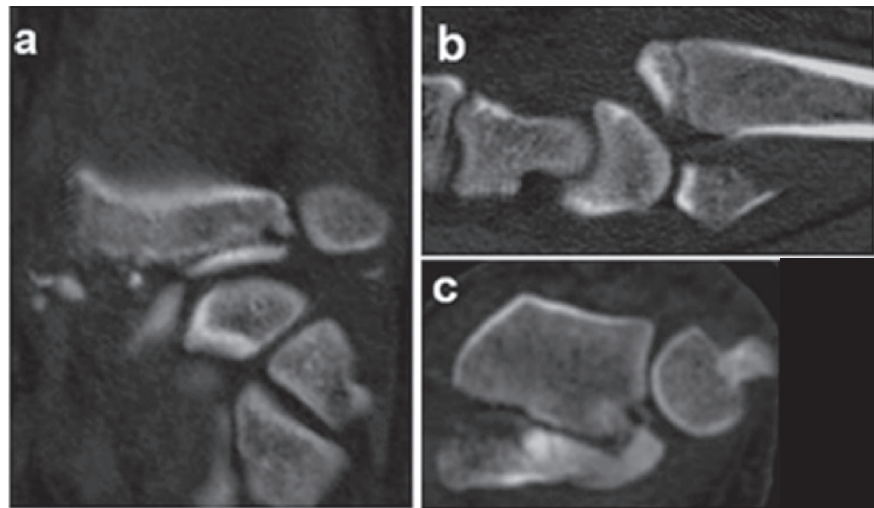

Figure 8. Tomographic images on coronal (A), sagittal (B) and axial (C) planes depicting intra-articular radiocarpal and distal radio-ulnar fracture of the distal end of the radius associated with radiocarpal volar dislocation, from subgroup IIIB. 

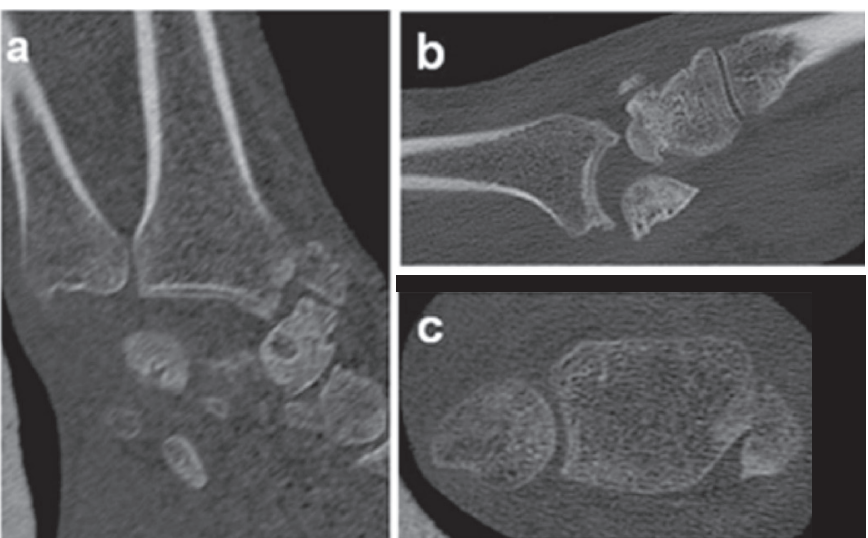

Figure 9. Tomographic images on coronal (A), sagittal (B) and axial (C) planes depicting intra-articular radiocarpal fracture associated with transscaphoid perilunate dislocation of the carpus, from subgroup IIIC.

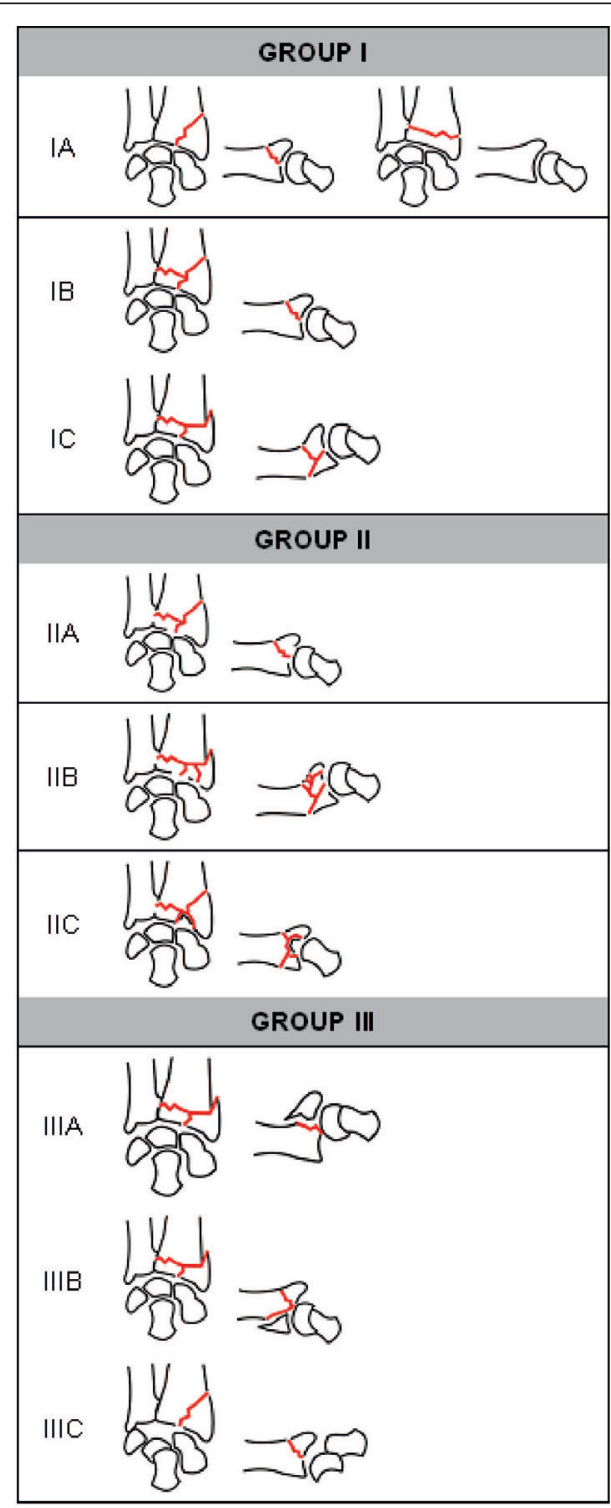

Figure 10. Schematic Drawing of the Tomographic Classification of the Hand Surgery Group of the hospital where the research was conducted. joint, distal ulnar-radial joint or both. The most prevalent fracture pattern was subgroup IIB (33 cases), i.e. fractures with spacing between articular fragments $\geq 2 \mathrm{~mm}$ associated with metaphyseal fragments and angulation $\geq 20^{\circ}$ and/or radial shortening $\geq 9 \mathrm{~mm}$, followed by subgroups IC (15 cases) and IIC (11 cases). The least prevalent patterns were subgroups IA, IB, IIIA and IIIC, all of which had only two cases each.

With regard to the groups, Group II fractures proved the most frequent (46 cases), followed by Group I (19 cases) and Group III (9 cases). Concerning patient age, mean age was 47.91 years overall (minimum 21 years and maximum 90 years), 54.63 years for Group I, 47.58 years for Group II and 34.55 years for Group III.

\section{DISCUSSION}

The emphasis placed on fracture classification systems in Orthopedics is explained by the fact that these can help dictate treatment and prognosis. Consequently, it is paramount that such systems are both reliable and reproducable. ${ }^{5}$

Computed tomography (CT) provides useful information for operative planning and can sometimes lead the surgeon to change a conservative approach in favor of surgical treatment due to the technique's greater reliability in quantifying intra-articular fragments compared with plain radiographs. ${ }^{6} \mathrm{CT}$ also yields additional information on articular misalignment, involvement of scaphoid and semi-lunate fossae and metaphyseal defects. ${ }^{4}$

Cole et al. ${ }^{7}$ stated that CT can be considered an adjuvant method, facilitating classification and treatment indication in fractures of the distal end of the radius. These authors reported that the complementary use of CT in more complex cases helps determine articular involvement, misalignment and fragmentation. This previous study was pivotal in the adoption of a new conception regarding classification based on tomography.

Our tomographic classification system is comprised by essentially articular distal radius fractures and does not cover extra-articular fractures, based on the premise that radiographic images on postero-anterior, profile, semi-pronated oblique and semi-supinated oblique views are invariably sufficient for diagnosing these lesions. Rozental et al. ${ }^{8}$ hold that CT has the advantage of more accurately revealing fractures of the sigmoid notch in $65 \%$ of cases. Our proposal classification includes the presence of articular involvement and spacing of both the radiocarpal and distal radio-ulnar joints. Moreover, under the new system proposal, the presence of depression of the sigmoid notch and semi-lunate and scaphoid fossae are regarded as a specific subgroup, since our in-depth analysis revealed that tomographic images allow clearer elucidation and quantification of irreducible impacted fragments.

Nowadays, it is clear that the paradigm of population aging is undergoing major changes, owing to the greater dissemination of the deleterious effects of sedentarism and smoking, and also through the incentive to change habits and life style to include a healthier diet and practice physical activities. These recommendations play a key role in preserving bone quality, and therefore we do not regard chronological age as an instability factor.

After observation of the tomographic images of the 74 cases of the present sample, some parameters were considered irreducible, including: a) Depression of the scaphoid and semi-lunate fossae and of the sigmoid notch: considered irreducible owing to the impossibility of returning the fracture fragments to their previous anatomic positions using closed reduction maneuvers and ligamentotaxis alone. We broadened this concept to include similar depression of the scaphoid fossa and sigmoid notch (Group II, subgroup IIC). Failure to recognize articular depressions can lead to collapse of the radiocarpal joint, with greater prevalence of osteoarthrosis, chronic pain and limitation in range of motion. 
b) Fracture-dislocation (dorsal radiocarpal, volar radiocarpal and perilunate): in Orthopedics, acute dislocations after trauma are known to be serious lesions with reserved prognosis that require immediate reduction of the joint. In the present classification, fractures-dislocations are pooled together in Group III, and are therefore deemed more serious than the other groups.

Under our tomographic classification, all fractures with articular spacing $\geq 2 \mathrm{~mm}$ are included in Group II, based on the view that this criteria is a factor associated with greater severity and instability compared to Group I. Dorsal angulation $\geq 20^{\circ}$ was also included in our classification as an instability factor in Group I, subgroup IC, and in Group II, subgroup IIB, but only where this deviation corresponded to a metaphyseal fragment associated with intra-articular fracture. Loss of radial height $\geq 9 \mathrm{~mm}$ was also included as another instability factor in Groups I and II, subgroups IC and IIB, respectively.

We elected to include fractures with single or multiple intra-articular fragments and spacing $\geq 2 \mathrm{~mm}$ in Group II (subgroup IIA), associated with metaphyseal fragment, comminuted or otherwise, with dorsal angulation $\geq 20^{\circ}$ and/or radial shortening $\geq 9 \mathrm{~mm}$ (subgroup IIB), and not to include metaphyseal dorsal fragmentation as a separate instability factor.

The inclusion of the distal ulna fracture as an isolated instability factor is debatable. We believe that stability should be tested pre-operatively, after stabilization of the fracture of the radius. Some authors indicate that surgical management is unnecessary unless the distal radio-ulnar joint is unstable after fixation of the fracture of the radius ${ }^{9}$

Burstein ${ }^{10}$ suggests that all classification systems be submitted to previous tests of reliability and reproducibility prior to their use. For the tomographic classification presented, reliability and reproducibility studies are planned to test the applicability of the system in routine practice.

Intra-articular distal radius fractures were organized into three larger groups in increasing order of severity (fractures without displacement, fractures with displacement and fractures-dislocations). Likewise, the subgroups were also organized into three divisions ( $A, B$ and $C$ ) again in increasing order of severity, starting with the fracture line of $<2 \mathrm{~mm}$ of spacing between fragments in the distal radio-ulnar or radiocarpal articulation (IA), in both distal and radio-ulnar and radiocarpal joints (IB) or either of the two joints associated with metaphyseal fragment with dorsal angulation $\geq 20^{\circ}$ and/or loss of radial height $\geq 9 \mathrm{~mm}$ (IC). These fractures generally have a good prognosis.
Group II fractures differ in severity from Group I fractures in that they have spacing between articular fragments $\geq 2 \mathrm{~mm}$. When there is only this intra-articular space, the fractures are considered to belong to subgroup IIA. If, besides the spacing $\geq 2 \mathrm{~mm}$, there is also the presence of metaphyseal fragment with angulation $\geq 20^{\circ}$ and/or radial shortening $\geq 9 \mathrm{~mm}$, these cases are classified into subgroup IIB. On the other hand, if the fracture has any depression of the scaphoid and semilunate fossae and/or of the sigmoid notch, irrespective of the presence of angulation and/or loss of radial height, they are deemed to have greater severity and complexity and are classified into the IIC subgroup. The prognosis is more disfavorable compared to the previous classification, given that failure to achieve harmonic reestablishment of the articular congruence can lead to collapse of the fragments, early osteoarthrosis, chronic pain in the hand and limitation in movements.

Lastly, Group III comprises all intra-articular fractures of the distal extremity of the radius associated with dislocation, irrespective of the presence or otherwise of spacing and articular depression, fragmentation, angulations and loss of radial height. These cases may present as radiocarpal dorsal dislocation (IIIA), radiocarpal volar dislocation (IIIB) or as intra-articular fracture of the distal end of the radius associated with perilunate dislocation of the carpus. These are extremely serious and complex lesions, associated with an unfavorable prognosis, particularly when not recognized and treated rapidly and effectively, potentially evolving to collapse of the fragments, early osteoarthrosis, articular block and chronic pain. In terms of limitations, although all 74 cases were included in our classification, a larger number of images could increase the confidence that many patterns of fracture are covered in the classification. Future studies including new images and investigations on reliability and reproducibility should be implemented so that this tomographic classification can be adapted if necessary and applied in clinical practice to help medical residents and surgeons by providing a more straightforward and reliable classification, establishing accurate treatment approaches and predicting the prognosis of lesions.

\section{CONCLUSION}

The tomographic classification proposal for distal radius fractures is applicable only to intra-articular fractures.

The tomographic classification proposal has the advantage of encompassing the known intra-articular patterns into only three groups, comprising nine logical easy-to-memorize possibilities in increasing order of severity of articular involvement.

AUTHORS' CONTRIBUTIONS: Each author made significant individual to the development of the study. VGN (0000-0003-0214-7746) *: was the main contributor in drafting the manuscript, collected clinical data, bibliographic research and statistical analysis; ACC (0000-0003-4499-5233) and SLC (00000002-9086-734X * : contributed to the intellectual concept and coordination of the study. ACC was responsible for guiding the others participants; LRS (0000-0002-0003-1144)*: and DFF (0000-0002-3833-5397)*: collected clinical data; VGN, ACC and IC (0000-0003-3870-0523)*: reviewed the manuscript. All authors reviewed the manuscript and contributed to the intellectual concept. ${ }^{\star}$ ORCID (Open Researcher and Contributor ID).

\section{REFERENCES}

1. Alffram PA, Bauer GC. Epidemiology of fractures of the forearm. A biomechanical investigation of bone strength. J Bone Joint Surg Am. 1962;44:105-14.

2. Evans S, David M, Quraishi MK, Hanif UK, Sadique H, Machani B. The use of plain radiographs in the classification of distal radius fractures. $\mathrm{J}$ Orthop. 2014;11(3):142-4.

3. Harness NG, Ring D, Zurakowski D, Harris GJ, Jupiter JB. The influence of three-dimensional computed tomography reconstructions on the characterization and treatment of distal radial fractures. J Bone Joint Surg Am. 2006;88(6):1315-23.

4. Pruitt DL, Gilula LA, Manske PR, Vannier MW. Computed tomography scanning with image reconstruction in evaluation of distal radius fractures. J Hand Surg Am. 1994;19(5):720-7.

5. Nascimento VG, da Costa AC, Falcochio DF, Lanzarin LD, Checchia SL, Chakkour I. Computed tomography's influence on the classifications and treatment of the distal radius fractures. Hand (N Y). 2015;10(4):663-9.
6. Arealis G, Galanopoulos I, Nikolaou VS, Lacon A, Ashwood N, Kitsis C. Does the CT improve inter- and intra-observer agreement for the AO, Fernandez and Universal classification systems for distal radius fractures? Injury. 2014;45(10):1579-84.

7. Cole RJ, Bindra RR, Evanoff BA, Gilula LA, Yamaguchi K, Gelberman RH. Radiographic evaluation of osseous displacement following intra-articular fractures of the distal radius: reliability of plain radiography versus computed tomography. J Hand Surg Am. 1997;22(5):792-800.

8. Rozental TD, Bozentka DJ, Katz MA, Steinberg DR, Beredjiklian PK. Evaluation of the sigmoid notch with computed tomography following intra-articular distal radius fracture. J Hand Surg Am. 2001;26(2):244-51.

9. Palmer AK. Fractures of the distal radius. In: Green DP. Operative Hand Surgery. New York, NY: Churchill Livingstone; 1993. p.929-967.

10. Burstein AH. Fracture classification systems: do they work and are they useful? J Bone Joint Surg Am. 1993;75(12):1743-4. 